\title{
Individuals with and without Schizophrenia: Do Physical Activity and Gender Differentiate them?
}

\author{
Konstantinidis Christos* and Bebetsos Evangelos \\ School of Physical Education \& Sport Science, Democritus University of Thrace, Komotini, Greece
}

\begin{abstract}
The study examined the relationship between exercise and health (mental and physical), of individuals classified as schizophrenic. In order to measure the physical possibilities of the sample, the "ALPHA-FIT battery test" for adults aged 18-69 years was used, while for recording the psychosomatic status, the "Subjective Exercise Experience Scale" was applied. The sample was consisted of 57 subjects, which were divided into three different groups. The results have shown that healthy self-esteem, physical condition and age are significantly related to the physical activity level of the participants. Regarding sex, no differences were indicated. Results pointed out that the Alpha-Fit test is suitable for usage on psychotic people to whom exercise plays a decisive factor of their psychological health.
\end{abstract}

Keywords: Schizophrenia; Gender; Physical activity

\section{Introduction}

To understand what schizophrenia is, it is advisable to have a clarification of what complicates the lives of people suffering from schizophrenia and what features lead psychiatrists to give to that people the diagnosis of schizophrenia. According to the positive symptoms of schizophrenia are an excess or distortion of normal functioning of the individual including delusions, hallucinations, disorganized speech and severe disorganized or catatonic behavior [1-3]. On the other hand, the negative symptoms of schizophrenia refer to a reduction or loss of normal function manifested as affective flattening, dumb, or lack of will. Additionally, cognitive deficits of schizophrenia related to attention problems, poor executive function on the planning and organization and memory impairment. These cognitive impairments often lead people with schizophrenia to a significant social and occupational dysfunction [3].

Concerning the relationship between schizophrenia and exercise, the role of physical activity for the physical and mental health of people with schizophrenia has not been studied extensively and is still a field promising further exploration [4]. It has been suggested that physical activity can improve the quality of life of adults with schizophrenia, offering physical and psychological benefits. The research about the psychiatric benefits of physical activity in adults suffering from schizophrenia, though still limited, shows that it can alleviate the negative symptoms of schizophrenia (in order to reduce depression, reduce social withdrawal and isolation and increase self-esteem) and provide an effective response strategy for the positive symptoms of schizophrenia [5].

The available demographic data of psychotic diseases, demonstrated that the incidence of schizophrenia varies considerably among countries $[6,7]$. Bibliography related to gender confirmed that men are more likely to develop symptoms of schizophrenia in comparison to women [7]. Additionally, the same researchers noted that is equally important the fact that immigrants were more prone to develop schizophrenia than the indigenous populations while people in urban areas have a higher risk of developing schizophrenia than those who live in mixed urban and rural areas. It is universally recognized, that further investigations will assess that the incidence of schizophrenia are needed to identify deviations in relation to the time and place.

Nevertheless, it seems that there is a way to improve these social difficulties. Significant effects arising from the involvement of exercise in the healing process of people suffering from schizophrenia. More particularly, the treatment of schizophrenia appears to lessen the symptoms of schizophrenia and depression in patients with schizophrenia than an occupational therapy based on exercise when performed once or twice a week for 1 hour. Also, the cardiovascular capacity in patients with schizophrenia shows to be improved under treatment of schizophrenia which is based on performance compared to occupational therapy [8].

In Greece, the diagnosis of schizophrenia is based on the criteria set out in the DSM classification manual [9]. According to DSM, typical symptoms are delusional ideas, hallucinations, disorganized speech, severely disorganized or catatonic behavior, and social and professional dysfunction. In Greece, it has been found that the general population keeps distances and rejects people with schizophrenia, much more than the general population in Germany and Canada [10,11]. It should be noted that the curriculum of undergraduate psychiatric training in Greece did not entail any specific anti-stigma training modules [11].

Curing schizophrenia is not an established tactic, a fact that raises suspicions about the effectiveness of each method. Although prescription drugs are similar across countries, the type of psychosocial intervention that is followed differs. Therefore, there is room for further testing and innovative efforts to help people with schizophrenia [12]. There is a variety of reasons for taking medication. The most common reasons for the use of antipsychotics are: good tolerance $(82.9 \%)$, efficacy against positive symptoms (77.7\%), improved compliance (56.5\%), ease of use for the patient (56.1\%) and efficacy against negative symptoms (52.96\%) [13].

\section{Aims of the study}

The purpose of the present study is to examine the relationship

*Corresponding author: Christos K, School of Physical Education \& Sport Science, Democritus University of Thrace, Komotini, Greece, Tel:+302531039712; E-mail: cris.konstantinidis@gmail.com

Received: July 07, 2017; Accepted: August 05, 2017; Published: August 12 , 2017

Citation: Christos K, Evangelos B (2017) Individuals with and without Schizophrenia: Do Physical Activity and Gender Differentiate them? J Psychiatry 20: 416. doi:10.4172/2378-5756.1000416

Copyright: $\odot 2017$ Christos K, et al. This is an open-access article distributed under the terms of the Creative Commons Attribution License, which permits unrestricted use, distribution, and reproduction in any medium, provided the original author and source are credited 
between physical activity and health, mental and physical, of those who are classified as schizophrenics. It should be mentioned that this was the first study in Greece, which used that specific questionnaire. Therefore, the uniqueness of the study underlies in the relationship between gender and physical activity (groups) of individuals classified as schizophrenics specifically in Greece.

\section{Methods}

\section{Participants and setting}

The study included 57 individuals, were 37 of them were psychiatric patients of the University Hospital in Alexandroupolis. More specifically, the sample was divided into three groups: (a) the first group consisted of 20 individuals $(\mathrm{n} 1=20)$ who received a psychiatric diagnosis of schizophrenia and were physically active, (b) the second group consisted of 17 individuals $(\mathrm{n} 2=17)$ who received a psychiatric diagnosis of schizophrenia without being physically active, and finally, (c) the third group of 21 individuals $(\mathrm{n} 3=21)$ (general public) who were physically active. The individuals of the first and the second group were diagnosed with schizophrenia, according to the Diagnostic and Statistical Manual of Mental Disorders, fourth edition (DSM-IV) [14]. In order for the study to take place, an official authorization by University Ethics Committee in cooperation with University Hospital of Alexandroupolis, was given. For the participation individuals were asked to complete a signed consent form.

\section{Measures}

Firstly, individuals indicated gender, age, and weight. Secondly, all groups completed the "Alpha-Fit battery test" for adult aged 18-69 years [1]. Additionally, they completed the Greek version [15] of S.E.E.S. questionnaire [2].

\section{More specifically, the survey included two different gauges:}

1) The first one was related to the recording of the level of the fitness of the participants while the second to the self-report of the psychological state of the sample. More specifically, for physical measurements the "ALPHA-FIT Battery Test for adults aged 18-69 [1], was used. This test can be used in order to observe the level of fitness in different populations, and identify those with increased risks for their health because of their poor sport level. It includes fitness tests for the musculoskeletal system, training on cardiopulmonary function machine, body composition and metabolism. More specifically, the test consists of seven areas, based on test data representing the most important fitness factors for health and physical function: two kilometers of walking and giving information on cardiopulmonary status, use the handle showing muscle power, jump-and-reach showing power leg, modified bends indicated at the top of the body and the muscular strength of the shank, standing on a leg showing the balance and body mass index, waist circumference as an indicator of obesity. Before administering the test, a health checklist is provided and included in the general context of the Alpha-Fit Test.

2) For the psychological measurements of the individuals, the "Subjective Exercise Experiences Scale" was used [2]. The specific questionnaire is a measurement of the overall psychological responses to stimulant characteristics of exercise. The scale consists of 12 questions, which form three factors: a) Positive Well-being (i.e., "I feel great"), b) Psychological Stress (i.e., "I feel Horrible") and, c) Fatigue (i.e., "I feel Drained"). The questions accompanied by a 7-point Likerttype scale responses, where $1=$ not at all, up to $7=$ very much. More specific, two of three factors correspond to the negative and positive terminals associated with psychological health (Positive Well-being, Psychological Stress), while the third represents the subjective indicator of "Fatigue". The research used the Greek version of the questionnaire [15].

\section{Data analysis}

Reliability and Univariate analysis were performed, using the statistical package S.P.S.S. 21.

\section{Results}

\section{Internal consistency}

The internal consistency of the SEES questionnaire was for: (a) "Fatigue" 0.90, (b) "Psychological Distress" 0.83, and (c) "Psychological Well-Being" 0.85 . The results indicate that all scales showed acceptable internal consistency.

\section{Univariate analysis}

Univariate Analysis were conducted to investigate any/or possible differences among the variables of "gender" and "physical activity" (groups). The analysis revealed the following statistical significant differences:

1) For the factor "Psychological Well-Being" (F2, 64=13.083; $\left.\mathrm{p}<0.05, \eta^{2}=0.231\right)$. More specifically, the post hoc multiple comparisons Scheffe test indicated the differences between the $2^{\text {nd }}$ group $(M=2.94$, $S D=0.074)$, with both the $1^{\text {st }}(M=5.07, S D=0.27)$, and the $3^{\text {rd }}(M=5.69$, $S D=0.27)$.

2) For the factor "Psychological Distress" (F2, 64=15.641; $p<0.05$, $\eta^{2}=0.159$ ). More specifically, the post hoc multiple comparisons Scheffe test indicated the differences between the $2^{\text {nd }}$ group $(M=3.82, S D=0.24)$, with both the $1^{\text {st }}(M=3.19, S D=0.26)$, and the $3^{\text {rd }}(M=1.88, S D=0.26)$.

3) For the factor "Fatigue" (F2, $\left.64=15.826 ; p<0.05, \eta^{2}=0,185\right)$. More specifically, the post hoc multiple comparisons Scheffe test indicated the differences only between the $2^{\text {nd }}$ group $(M=3.93, S D=0.31)$, and the $3^{\text {rd }}(M=2.77, S D=0.35)$.

4) For the factor "Encumbrance" (F2, 64=15.826; $\left.p<0.05, \eta^{2}=0.063\right)$. More specifically, the post hoc multiple comparisons Scheffe test indicated the differences between the $3^{\text {rd }}$ group $(M=1.54, S D=0.26)$, with both the $1^{\text {st }}(M=2.96, S D=0.26)$, and the $2^{\text {nd }}(M=3.48, S D=0.24)$.

5) For the factor "Physical Activity" (F2, 64= 68.669; $\mathrm{p}<0.05$, $\left.\eta^{2}=0.303\right)$. More specifically, the post hoc multiple comparisons Scheffe test indicated the differences between the $2^{\text {nd }}$ group $(M=1.49, S D=0.24)$, with both the $1^{\text {st }}(M=4.75, S D=0.26)$, and the $3^{\text {rd }}(M=5.19, S D=0.26)$.

6) a) For the factor "Health Self-esteem" (F1,64= 4.448; $\mathrm{p}<0.05$, $\left.\eta^{2}=0.192\right)$. More specifically, the post hoc multiple comparisons Scheffe test indicated the differences between the $3^{\text {rd }}$ group $(M=4.46, S D=0.24)$, with both the $1^{\text {st }}(M=3.40, S D=0.24)$, and the $2^{\text {nd }}(M=2.82, S D=0.22)$.

b) Additionally, women achieved higher scores $(M=3.84, S D=0.20)$, than men $(M=3.28, S D=0.18)$.

7) For the factor "Psycho-Social Age" (F2, 64=24.295; p $<0.05$, $\left.\eta^{2}=0.71\right)$. More specifically, the post hoc multiple comparisons Scheffe test indicated the differences between the $2^{\text {nd }}$ group $(M=2.02, S D=0.21)$, with both the $1^{\text {st }}(M=3.35, S D=0.23)$, and the $3^{\text {rd }}(M=4.15, S D=0.23)$.

\section{Discussion and Conclusion}

The purpose of this study is to examine the relationship between 
physical activity and health, mental and physical, of those who are classified as schizophrenics. To our knowledge, no similar studies have been conducted on the specific topic in Greece. Therefore, discussion and conclusions from the present study reflect a first attempt to interpret the relation of physical activity on psychotics.

More specifically, results revealed that exercise had a positive effect and increased "Psychological Well-Being" to people who are physically active ( $1^{\text {st }}$ and $3^{\text {rd }}$ groups), regardless of whether they have received a psychiatric diagnosis. This was confirmed by previous researches, as it has repeatedly demonstrated that physical activity is associated with improved psychological well-being, physical health, life satisfaction, and cognition [16,17]. In contrast, the only group that was differentiated to this factor was the $2^{\text {nd }}$ one, because the individuals were inactive.

The same applied to the "Psychological Distress" of the individuals. The groups who exercised had the same results while still only group which not practiced differed. The second group had the highest index. This result comes to confirm the findings of older researches that have shown that Psychological Distress is reduced with the use of sports [18].

For the "Fatigue" factor, differences exist only among people who have received psychiatric diagnosis and those that are physical active without having received a psychiatric diagnosis. This result agrees with previous researches $[19,20]$, according to which fatigue increases in the patient group too. The higher fatigue level is confirmed from other psychological diseases too, as depressed person [21]. It should be noted that depression is one of the most common symptoms of schizophrenia.

In the factor "Encumbrance", differences were appeared among people who belong to the general population and people who have received psychiatric diagnosis, trainees and non. Researchers hypothesized that that chronic use of medications which causes total body suppression [22], might be the answer.

On the other hand, significant attention should be paid to the fact that "Physical Activity" varies among individuals who do not exercise and those who exercised, regardless of whether they have received a psychiatric diagnosis. These two results are consistent with the literature $[16,17]$ as mentioned above.

Furthermore, results showed that "Health Self-esteem" of people suffering from schizophrenia does not vary, whether they exercised or not. In contrast, there is difference in health self-esteem between individuals of the general population and those recorded as schizophrenics. But this result is contradictory with earlier research [5], were exercise increased health self-esteem of schizophrenics. The researchers assume that this contrast may be due to the different treatment of schizophrenic patients, as shown in literature [10,11], in countries where the investigations took place.

On the contrary, at the factor "Psycho-Social Age" differences appeared among individuals of group 2 with groups 1 and 3. "PsychoSocial Age" is the individual feeling concerning the age and projects it to his surroundings in relation to his biological age. Research shows that physical activity makes people feel younger, whether they have been diagnosed with schizophrenia or not, so they feel better with themselves. It is also bibliographically supported [22], that psychosocial rehabilitation programs could be helpful for people with long-term mental illness.

\section{Gender}

The bibliography review, concerning schizophrenia and its relationship to gender and physical activity, shows that the results are ambiguous. In some countries, it seems that demographic data of patients are differentiated according to gender [23,24]. In contrast, there are studies that claim there are no differences in sex factor [25-27].

Thus, in current research it is argued that there are gender differences in the factor of "Health Self-esteem". But the difference between previous studies and this present one is that in this research, it was found that women show higher scores than men, on the contrary with others which claim that males have larger health self-esteem [2428]. Gender differences may be due to socially determined gender norms, roles and responsibilities, which place women at a disadvantage against men on issues related to their lives or it may be a function of perinatal complications [24-29]. The researchers assume that the contradictory result is due to different gender roles and responsibilities in Greece on the contrary with other countries.

Previous studies estimated that it has been repeatedly proven that physical activity is related to improved psychological well-being, physical health, life satisfaction, and cognitive function [16,17]. These data are also confirmed about the population used in the survey. From the results, becomes clear the positive relation of physical activity to the well-being of individuals. This conclusion could serve as a springboard for future researches into improving the mental health of people diagnosed with a mental disorder.

In future researches, it would be a good idea to try to implement an exercise program tailored to the specificities, physical and intellectual, of people with schizophrenia. Also, the necessity to explore ways to instigate the need and contribution of the exercise of people with mental illness to those who are responsible on a daily basis for the care and treatment of these individuals is arisen. Medical staff, therapists and caregivers would find it helpful to understand how useful a physical exercise can be in improving people with schizophrenia.

\section{Limitations}

Achilles heel of the studies in this population was the small number of sample. The same problem occurred in the present study. The aim should be to enroll more patients in future studies to validate findings. Yet another restriction was the use of medication factor. In this study, this factor was not measured.

\section{Acknowledgements}

Authors would like to thank Dr. Samakouri Maria, Associate Professor of Medical School of University Hospital of Alexandroupolis and her co-worker Mrs. Arvaniti Aikaterini, for their active participation and support. Also, they want to give thank to the workers operators for their crucial help regarding the data collection. Last but not least want to thank Mrs. Kyriaki Anthopoulou, English language teacher for her advice regarding the syntactic and textual appropriateness concerning the written text.

\section{References}

1. Suni J, Husu P, Rinne M (2008) Fitness for health: The alpha-fit test battery for adults aged.

2. McAuley E, Courneya KS (1994) The subjective exercise experiences scale (SEES): Development and preliminary validation. JSEP 16: 163-177.

3. Janney CA (2012) Physical activity in overweight and obese adults with schizophrenia and schizoaffective disorders. Doctoral Dessertation, University of Pittsburgh.

4. Taylor AH, Faulkner G (2008) Inaugural editorial. Ment Health Phys Act 1: 1-8.

5. Faulkner G (2005) Exercise as an adjunct treatment for schizophrenia. In Faulkner G, Taylor A (eds.). Exercise, health, and mental health: Emerging relationships. Routledge, London.

6. McGrath J, Saha S, Welham J, El Saadi O, MacCauley C, et al. (2004) A systematic review of the incidence of schizophrenia: The distribution of rates and the influence of sex, urbanicity, migrant status and methodology. BMC Medicine 2: 13.

7. Saha S, Chant D, Welham J, McGrath J (2005) A systematic review of the 
Citation: Christos K, Evangelos B (2017) Individuals with and without Schizophrenia: Do Physical Activity and Gender Differentiate them? J Psychiatry 20: 416. doi:10.4172/2378-5756.1000416

prevalence of schizophrenia. PLoS Medicine 2: 141

8. Scheewe TW, Backx FJG, Takken T, Jörg F, Van Strater ACP, et al. (2013) Exercise therapy improves mental and physical health in schizophrenia: A randomised controlled trial. Acta Psychiatrica Scandinavia 127: 464-473.

9. Manos N (1997) Key elements of Clinical Psychiatry. University Studio Press, Thessaloniki.

10. Economou M, Richardson C, Gramandani C, Stalikas A, Stefanis C (2009) Knowledge about schizophrenia and attitudes towards people with schizophrenia in greece. Int J Soc Psychiatry 55: 361-371

11. Economou M, Peppou LE, Louki E, Stefanis CN (2012) Medical students' beliefs and attitudes towards schizophrenia before and after undergraduate psychiatric training in Greece. Psychiatry Clin Neurosci 66: 17-25.

12. Gaebel W, Weinmann S, Sartorius N, Rutz W, McIntyre JS (2005) Schizophrenia practice guidelines: International survey and comparison. Br J Psychiatry 187: 248-255.

13. Papageorgiou G, Capas F, Zink M, Rossi A (2011) Country differences in patient characteristics and treatment in schizophrenia: Data from a physicianbased survey in Europe. Elsevier Masson. Eur Psychiatry 26: 17-28.

14. American Psychiatric Association (APA) (2000) Diagnostic and statistical manual of mental disorders (4thedn.). American Psychiatric Association, Washington DC. p. 866.

15. Kouli O (1996) Students orientation to ego and to task during the execution of sports activity in physical education class. Unpublished Thesis, Democritus University of Thrace, Komotini, Greece.

16. Meyer JM, Davis VG, Mcevoy JP, Davis VG, McEvoy JP, et al. (2008) Impact of antipsychotic treatment on nonfasting triglycerides in the CATIE Schizophrenia Trial phase 1. Schizophr Res 103: 104-109.

17. Goodwin RD (2003) Association between physical activity and mental disorders among adults in the United States. PVM 36: 698-703.

18. Li F, Duncan TE, Duncan SC, McAuley E, Chaumeton NR, et al. (2001) Enhancing the psychological well-being of elderly individuals through Tai Chi exercise: A latent growth curve analysis. SEM 8: 53-83.

19. Bodin T, Martinsen EW (2004) Mood and self-efficacy during acute exercise in clinical depression. A randomized controlled study. JSEP 26: 623-633.

20. Malchow B, Reich-Erkelenz D, Oertel-Knöchel V, Keller K, Hasan A, et al. (2013) The effects of physical exercise in schizophrenia and affective disorders. Eur Arch Psychiatry Clin Neurosci 263: 451-467.

21. Weinstein AA, Deuster PA, Francis JL, Beadling C, Kop WJ (2010) The role of depression in short-term mood and fatigue responses to acute exercise. Int $\mathrm{J}$ Behav Med 17: 51-57.

22. Fogarty M, Happell B (2005) Exploring the benefits of an exercise program for people with schizophrenia: a qualitative study. Issues Ment Health Nurs 26: 341-351.

23. Häfner H, An der Heiden W (1997) Epidemiology of schizophrenia. CJP 42 139-151.

24. Gangadhar BN, Panner Selvan C, Subbakrishna DK, Janakiramaiah N (2002) Age at onset and schizophrenia: reversed gender effect. Acta Psychiatr Scand 105: 317-319.

25. Murthy GV, Janakiramaiah N, Gangadhar BN, Subbakrishna DK (1998) Sex difference in age at onset of schizophrenia: discrepant findings from India. Acta Psychiatr Scand 97: 321-325.

26. Naqvi H, Khan MM, Faizi A (2005) Gender differences in age at onset of Schizophrenia. J Coll Physicians Surg Pak 15: 345-348.

27. Naqvi I, Murtaza M, Nazir MR, Naqvi HA (2010) Gender difference in age a onset of schizophrenia: A cross sectional study from Pakistan. JPMA 60: 886.

28. Derdikman-Eiron R, Indredavik MS, Bratberg GH, Taraldsen G, Bakken IJ, et al. (2011) Gender differences in subjective well-being, self-esteem and psychosocial functioning in adolescents with symptoms of anxiety and depression: findings from the nord-trøndelag health study. Scand J Psychol 52: 261-267.

29. World Health Organization (2002) Gender and mental health. 